\title{
Espaço urbano e suas transformações pela lente da semiótica urbana
}

\author{
Urban space and its transformations by the lens of urbansemiotics
}

\begin{abstract}
Adriano Rodrigues de Almeida - Universidade Estadual de Londrina I Londrina I PR I Brasil I adrianoralmeida@hotmail.com (1) 000-0002-3646-1613
\end{abstract}

Desire Blum Menezes Torres - Universidade Estadual de Londrina I Londrina I PR I Brasil I desire_menezestorres@yahoo.com.br 0000-0002-6272-9943

Resumo: Entendendo a cidade como produtora de sentido por meio de suas imagens, fazse necessário compreender como estes signos influenciam a paisagem urbana. O objetivo da pesquisa é examinar o potencial de influência da imagem do varejo nas transformações da espacialidade urbana, sendo suas especificidades verificar os lugares de fixos e de fluxos; verificar a história ambiental e sua relação com o usuário; identificar as transformações físico-contextuais da imagem do varejo. A metodologia consiste em uma pesquisa descritiva, qualitativa, com aplicação de técnicas de observação, pesquisa documental e bibliográfica, e a interpretação dos dados pelo viés da semiótica urbana. São comparadas imagens fotográficas da cidade de Londrina-PR obtidas do mesmo espaço urbano, cujo recorte temporal nas décadas de 1940 e 2010. A análise permite inferir que a cidade, enquanto produtora de sentido por meio de suas imagens constrói sua paisagem utilizando como suporte a comunicação da sua espacialidade.

Palavras-chave: Espaço urbano. Comunicação. Semiótica urbana. Varejo e consumo.

Abstract: Understanding the city as a producer of sense by means of its images, it is necessary to understand how these signs influence the urban landscape. The objective of the research is to examine the potential influence of the image of retail in the transformations of urban spatiality, whose specificities are: to verify the places of fixed and fluxes; verify the environmental history and its relation with the user; to identify the physical-contextual transformations of the retail image. The methodology consists of a descriptive, qualitative research, with application of observation techniques, documentary and bibliographical research, and the interpretation of the data by the bias of urban semiotics. One compares some photographic images of the city of Londrina-PR, obtained from the same urban space, whose temporal cut is in the decades of 1940 and 2010. The analysis allows to infer that the city, as a producer of meaning through its images, builds its landscape using as its support, the communication of its spatiality.

Keywords: Urban space; Communication; Urban semiotics; Retail and Consumption.

http://doi.org/10.22484/2318-5694.2019v7n14p179-198

Recebido em novembro 2018 - Aprovado em fevereiro 2019 


\section{Introdução}

Entendendo a cidade como produtora de sentido por meio de suas imagens, se faz necessário compreender como esses elementos significativos influenciam as paisagens urbanas através das transformações ocasionadas, pelos usos dos indivíduos nestes ambientes urbanos, bem como pela cultura que emerge dos modos de consumo e usos do varejo.

Os comportamentos e linguagens dos usuários são regidos por meio do desenvolvimento da cultura do consumo, a linguagem comercial e seus significados são diretamente relacionados à vendabilidade; consumir é se tornar parte de um todo social, estar inserido na sociedade. (BAUMAN, 2008).

Esta relação transmite em seu discurso a ideologia cultural capitalista, e este tipo de relação enraíza em seus consumidores uma unicidade de conceitos e preceitos que não valorizam as relações humanas e o uso consciente dos ambientes urbanos, não permitindo ou possibilitando a estes usuários compreender a importância do seu papel na construção da harmonia destes ambientes (BAUMAN, 2008).

Diante do exposto sobre os discursos do varejo e seus efeitos na espacialidade urbana, esta pesquisa tem como objetivo geral analisar o potencial de influência da imagem do varejo nas transformações da espacialidade urbana, tendo como especificidades verificar os lugares de fixos e de fluxos; verificar a história ambiental e sua relação com o usuário; identificar as transformações físico-contextuais da imagem do varejo.

Escolhe-se como objeto para esta pesquisa a região central da cidade de Londrina-PR. A motivação para esta escolha se dá pela significação do consumo nesse espaço urbano do munícipio, uma vez que se encontram diversos estabelecimentos varejistas/comerciais nesta localidade, além de conter valor histórico e simbólico para diversos estudos sócios culturais. Adota-se como suporte para análise a documentação visual, por meio de 
imagens fotográficas do objeto pesquisado, tendo como recorte temporal o período da década de 1940 e 2018.

Metodologicamente, caracteriza-se como uma pesquisa qualitativa, que utiliza como método a pesquisa documental e bibliográfica e, para a interpretação dos dados, os métodos da semiótica urbana da autora Lucrécia D'Aléssio Ferrara (1988). Dadas às informações que impulsionam esta pesquisa, abordam-se as fundamentações teóricas que vão nos acompanhar na compreensão dos conceitos.

\section{Semiótica urbana}

A semiótica permite analisar, em sua maioria, as coisas com as quais nos relacionamos, uma vez que o cérebro humano reproduz mentalmente todas as coisas reais, o que faz de tal objeto um signo que pode ser interpretado semioticamente. Ferrara (1988, p. 20) argumenta que "[...] a semiótica, como lógica da linguagem, ocupa-se do signo enquanto representação do objeto, e do significado enquanto elemento essencial do conhecimento", sendo a semiótica, a partir de uma concepção científica, o estudo lógico da linguagem.

A dimensão simbólica está ligada à representação dos pensamentos em signos, permitindo assim a interpretação do mundo em que se vive e dos objetos com que se relaciona. Neste cenário para o entendimento e percepção dos signos dos espaços urbanos Ferrara (1988) defende que, inicialmente, deve-se valorizar a percepção urbana como um todo e compreender as imagens urbanas como fonte de informação sobre a cidade.

As interações comunicacionais da cidade e seus usuários, suas linguagens e cultura, produzem significantes, "[...] a paisagem corresponde a uma forma visual da materialidade urbana, mas construída pelo imaginário que se amplia em múltiplos contornos" (FERRARA, 2012, p. 47). Utiliza-se o conceito da semiótica urbana, teoria que estuda os significados 
e sentidos que emergem dos ambientes urbanos, permitindo compreender a cidade por meio de suas características físicas, bem como dos seus contextos sócios culturais (FERRARA, 1988, 2004; 2012).

A leitura destes ambientes pela ótica da semiótica urbana visa identificar características físico-contextuais não verbais que auxiliem na compreensão, como "leitores de linhas, traços, cores, sinais, gráficos, letras, números, frases, formas, volume, massas, movimentos: forças que interagem." (FERRARA, 1988, p. 31).

Embasados no conceito teórico que estuda os significados e sentidos que emergem dos ambientes urbanos, Ferrara (1988) nos permite compreender a cidade por meio de suas características físicas, bem como dos seus contextos sócios culturais. É preciso entender e compreender seus elementos e dela abstrair as relações significativas, realizando uma leitura pela percepção dos significados dos signos.

Contribuindo para a solidificação dos espaços, os estudos de Canevacci (1997) incorporam pressupostos sobre as dimensões do aparato simbólico da cidade. Relata que a concretização dos ambientes urbanos pode ocorrer se entender e compreender a cidade como um organismo subjetivo que cria e inventa comportamentos e valores por intermédio de linguagens próprias, baseada nas ações dos indivíduos que habitam o espaço urbano.

As dimensões da imagem da cidade constituem o quadro de uma interação comunicativa que define uma nova lógica visual e nos permite estudar aquela imagem entendendo-se a cidade como apoio material e signo dos processos culturais daquela visualidade (FERRARA, 2004, p. 21).

Esta afirmação nos permite compreender que "a paisagem corresponde a uma forma visual da materialidade urbana, mas construída pelo imaginário que se amplia em múltiplos contornos". (p. 47). Ferrara conclui: 


\section{tríade}

Desse modo, a paisagem urbana depende do valor subjetivo e sentimental que a contamina; porém, quando é apropriada pelos veículos de comunicação, seus fragmentos assumem uma espécie de função econômica e o valor da imagem pode ser análogo àquele do solo urbano, obedecendo a similares estratégias comerciais e persuasivas. (p. 47).

Assim, a paisagem da cidade, compreendida por este sentido, é assimilada e entendida de forma natural por suas interações e comunicações, já que não acontece sem registros, também não se "dispensa vínculos afetivos" (FERRARA, 2012, p. 48). "Todo uso urbano é uma revelação mais ou menos declarada que, despertando uma leitura crítica, permite chegar ao projeto que lhe deu origem, à história urbana e cultural à qual pertence." (FERRARA, 1988, p. 57).

\section{Fixos e fluxos da cidade}

As relações contemporâneas e seus movimentos produzem transformações sociais e espaciais, e utilizam como suporte a comunicação por meio do sentido e da linguagem, do subjetivo e o material. Considerando-se o conceito de Espaços, Santos (1994, 2007, 2008) elaborou estudos sobre a espacialidade urbana. O autor vislumbra a possibilidade de identificação de diversos tipos de lugares e, através da compreensão de suas relações e interações nos ambientes onde ocorrem os fatos e eventos, podem ou não exercer algum tipo de influência de significação ou de comunicação sobre as transformações dos espaços urbanos.

Santos $(1994,2007,2008)$ aborda, em diversos estudos, o conceito de fixos e fluxos, tratando-os como elementos transformadores do espaço e da sociedade. O autor defende que, por intermédio dos lugares, vistos como suportes para interações de pessoas, é que ocorrem as mudanças nos espaços. Afirma também que, a partir dos lugares, há a renovação das 
experiências e das relações, com o outro e com os ambientes, entendendo assim o passado, vivendo o presente e construindo o futuro.

Entendem-se como fixos "[...] os objetos materiais, isto é, aquilo que é concreto, material, que sofreu um processo de transformação ou criação humana e passou a adquirir uma função, um sentido" (SANTOS, 1994, p. 83). Santos (1994) considera que o espaço é constituído por estes fixos: casas, lojas, prédios, indústrias, entre outros, entendendo que estes estão presentes nas esferas sociais e econômicas e em suas mais variadas formas. Pontuando algumas considerações, o autor relaciona estes fixos a ambientes públicos e ambientes privados, e analisa as funções que os diferenciam dentro do espaço urbano:

Os fixos são econômicos, sociais, culturais, religiosos, etc. Eles são, entre outros, pontos de serviço, pontos produtivos, casas de negócios, hospitais, casas de saúde, ambulatórios, escolas, estádios, piscinas, e outros lugares de lazer. Mas se queremos entender a cidade não apenas como um grande objeto, mas como um modo de vida, há que distinguir entre os fixos públicos e os fixos privados. Estes são localizados segundo a lei da oferta e da procura, que regula também os preços a cobrar. Já os fixos públicos se instalam segundo os princípios sociais, e funcionam independentemente das exigências do lucro (SANTOS, 2007, p. 142).

A concepção do conceito de fluxo de Santos (1994) está relacionada a ações, ao movimento, a prática, e que é entendido como uma força que dá dinâmica aos fixos. O autor admite que "os fluxos são um resultado direto ou indireto das ações e atravessam ou se instalam nos fixos, modificando a sua significação e o seu valor, ao mesmo tempo em que, também, se modifica." (SANTOS, 2008, p. 62). Esta afirmação permite inferir que os fluxos oportunizam aos fixos movimentar-se, executar suas funções.

Os fixos e fluxos representam, por meio da interatividade de seus elementos, os lugares em uma análise da realidade dentro dos espaços. 
Entendendo este conceito, nota-se que ambos executam funções totalmente díspares, mas estão constantemente ligados, em contato interacionais, sendo mediados por circunstâncias e fatores sociais, históricos e culturais.

\section{Consumo e Interações sociais}

O consumo é uma ação humana sob influência de desejos, valores individuais, coordenada sob a influência direta do seu intelecto, o qual modela e direciona o comportamento e personalidade do indivíduo. Sendo esta ação individual ou coletiva, torna-se um ato reproduzido dentro de um sistema de relações socioculturais que absorvem os sentidos dos elementos imagéticos comerciais, expostos na visualidade cotidiana.

Aborda-se aspectos culturais e suas relações comerciais constituintes da sociedade moderna por meio do conceito de liquidez nas relações sociais do teórico Bauman (2008), que tece sua crítica ao modo em que o consumo se apropriou da vida dos indivíduos, tornando-a um bem de consumo. Em sua concepção,

o "consumismo" é um tipo de arranjo social resultante da reciclagem de vontades, desejos e anseios humanos rotineiros, permanentes e, por assim dizer, "neutros quanto ao regime", transformando-os na principal força propulsora e operativa da sociedade (BAUMAN, 2008, p. 41).

O teórico reitera que, em uma sociedade de consumidores, todos precisam ser e ter o consumo como vocação, onde, neste contexto social, o consumo visto e tratado desta maneira é "ao mesmo tempo um direito e um dever do indivíduo sem reconhecimento de exceção, não reconhecendo diferenças de idade, gênero, cultura ou de classe social" (BAUMAN, 2008, p. 73). 


\section{tríade}

Na concepção de Bauman (2008), o ato de consumir ganhou novos sentidos por meio do desenvolvimento da cultura do consumo contemporânea. Esta relação assumiu um novo papel, por se estruturar na fluidez e rapidez dos negócios, nos possibilita afirmar que o consumo é elemento formador de identidade, orientando o comportamento dos indivíduos.

É necessário combater a alienação imposta pelo sistema por meio da desconstrução dos discursos do consumo embutidos nos bens de consumo, que transformam a si, aos ambientes e aos espaços que se relacionam, bem como na estrutura construtivas dos pilares sociais.

\section{Metodologia}

A metodologia utilizada caracteriza este estudo como uma pesquisa descritiva, e emprega a técnica de observação do espaço urbano em questão e as demais interações com o mesmo. O corpus metodológico consiste em um trabalho qualitativo, com a utilização de técnicas de pesquisa documental e bibliográfico, e, para a interpretação dos dados, os métodos da semiótica urbana, realizada com base na comunicação urbana (FERRARA, 1988, 2004, 2012; SANTOS, 1994, 2007, 2008).

A pesquisa de campo ocorreu de forma exploratória e qualitativa e nos permitiu abordar os fenômenos sociais e explicá-los por meio da compreensão da vivência dos usuários, analisando as experiências do indivíduo e dos grupos sociais em suas linguagens e interações comunicacionais, permitindo relacionar questões socioculturais, obtidas por meio de investigação documental e bibliográfica. (MARCONI; LAKATOS, 2002).

O objeto de pesquisa deste artigo é o comércio varejista da rua Rio de Janeiro, uma das ruas comerciais mais importantes do centro da cidade de Londrina-PR, região de comércio escolhida, devido sua representação 
histórico social. Segundo Marconi e Lakatos (2002, p. 83) este tipo de pesquisa é "utilizada com o objetivo de conseguir informações e conhecimentos acerca de um problema para qual se procura uma resposta ou de uma hipótese que se queira comprovar ou ainda descobrir novos fenômenos ou as relações entre eles".

Escolhe-se a documentação visual fotográfica para análise do objeto desta pesquisa. Nas palavras de Coutinho (2012), a imagem é toda forma visual gerada pelo indivíduo, seja em forma abstrata, por meio pictóricos, registro "foto mecânico", ou mesmo em formações mentais da imagem (pensamentos). A mesma autora complementa que "é precisamente essa capacidade das imagens de comunicar uma mensagem que constitui o aspecto principal de sua análise" (COUTINHO, 2012, p. 330).

As fotografias analisadas são recortes concebidos em tempos distintos entre 1940 e 2018. Esta opção, intrinsicamente relacionada ao seu poder de comunicação, serviu como instrumento de ilustração da imagem da cidade, e, pelos elementos sígnicos dispostos nelas, decodifica-se seus sentidos e significados (FERRARA, 2004). Segundo Pierre Bourdieu e MarieClaire Bourdieu (2006), as imagens fotográficas possuem poder de registrar relações sociais, afirmando que "Por isso, as fotografias são vistas e apreciadas não em si mesmas e por si mesmas, isto é, em termos das suas qualidades técnicas ou estéticas, mas como "sociogramas" leigos que possibilitam um registro visual das relações e papéis sociais existentes" ( $p$. 31)

São analisadas fotografias concebidas em tempos distintos, obtidas através de pesquisa documental, bibliográfica e pesquisa de campo por meio de observação direta datada de abril 2018. Esta abordagem permite levantar dados para a pesquisa, estudando os fatos ocorridos antes, posteriormente ou mesmo diretamente no local do fenômeno (MARCONI; LAKATOS, 2002). 


\section{tríade}

Para a interpretação dos dados obtidos em análise, utiliza-se o conceito da semiótica urbana de Ferrara (1988), a qual elenca aspectos importantes, categorizando-os para melhor auxílio na abordagem dos fenômenos dos espaços urbanos por meio da semiótica, dentre eles: 1) as características físico-contextuais: estágio atual e sua transformação; 2) a memória e a história ambiental: o repertório urbano; os quais são utilizados para compreensão do objeto pesquisado.

Ainda dentro dos estudos semióticos da percepção urbana, Ferrara (1988) cede seus saberes descrevendo "técnicas de pesquisas" que destacam pontos relevantes do objeto a serem interpretados. Utiliza-se para iluminar esta análise: a) documentação iconográfica (mapas, croquis, plantas, fotos e desenhos) conservada em arquivos e/ou bibliotecas; b) documentação visual: fotográfica, de caráter seletivo e tendente a flagrar contrastes e semelhanças. Um recurso que tende a ser um filtro da informação: esta etapa é, operacionalmente, a mais eficiente no levantamento de dados, de ser executada pelos usuários, visto que a seleção de ângulos fotografados deve corresponder ao próprio uso ambiental, sendo, portanto, fator de percepção.

Para contribuição da análise e interpretação da espacialidade urbana, utiliza-se as análises do espaço do teórico Santos (1994, 2007, 2008) para compreender o conceito de fixos e fluxos e iluminar nosso objeto de pesquisa, explorando o ponto de investigação de Santos (1994) que aborda a relação entre espaço público e privado por meio dos fixos e fluxos, como produzem e transmitem informações. 


\section{Análise dos dados}

A análise foi realizada sobre os dados coletados das fotografias da rua Rio de Janeiro, localizada na região central, na cidade Londrina- PR, datadas nas décadas 1940 e de 2010. A percepção urbana analisou a cidade por dois setores: o físico e suas características, e os ambientes onde os sujeitos realizam suas atividades diárias, numa perspectiva comparativa urbana das transformações urbana, seguindo assim, uma das técnicas para analisar os signos urbanos, com a utilização do recurso fotográfico (FERRARA, 1988). Desta forma, três segmentos da análise dos dados coletados foram realizados, com base nas figuras 1 e 2, intitulados: Fixos e Fluxos: o repertório urbano; História ambiental e sua relação com o usuário; e Características físico-contextuais: estágio atual e sua transformação.

Figura 1: Cidade de Londrina-PR - décadas 1940 e 2010 - Rua Rio de Janeiro.

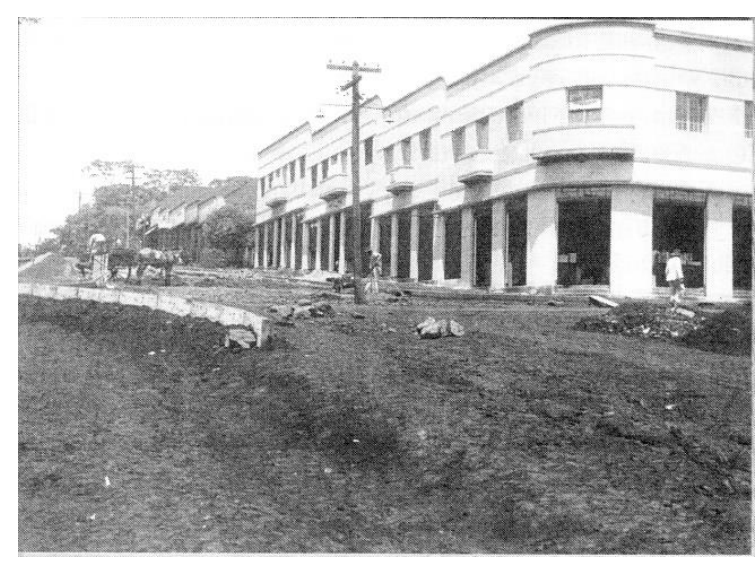

Foto 1: Londrina, década de 1940. Fonte: Livro Transformações Urbana, 2017.

Fotógrafo: Oswaldo Leite.

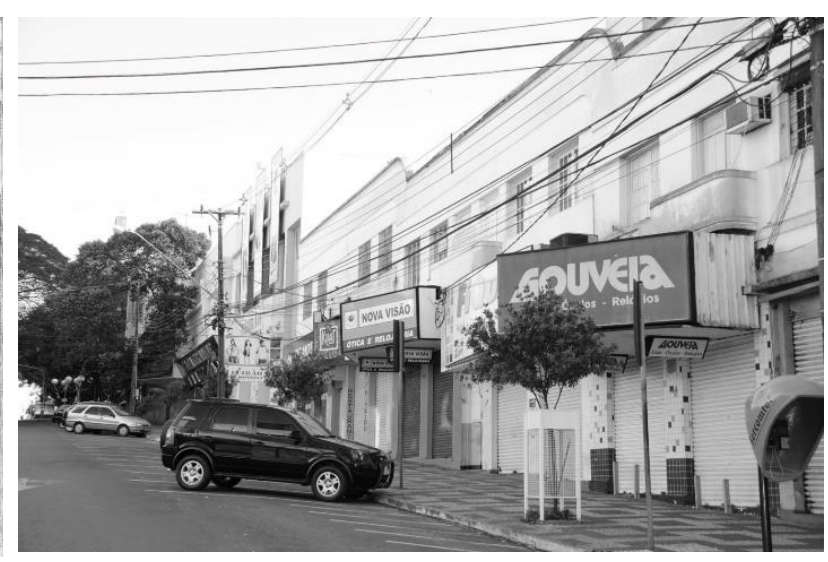

Foto 2: Londrina, 2010. Fonte: Livro Retratos da Cidade, 2014. Fotógrafo: Fernanda G. Bressan. 


\section{tríade}

Figura 2: Cidade de Londrina-PR - décadas 1940 e 2010 - Rua Rio de Janeiro.

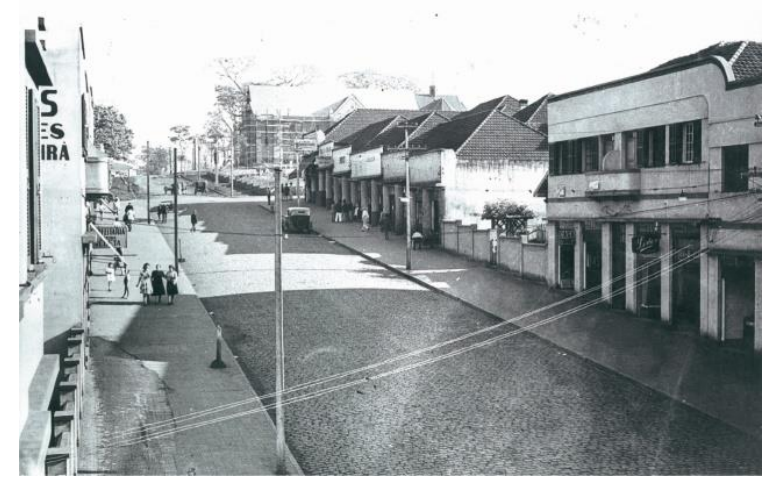

Foto 3: Londrina, década de 1940.

Fonte: Livro É de sonho e de pó, 2015. Fotógrafo: Carlos Stenders.

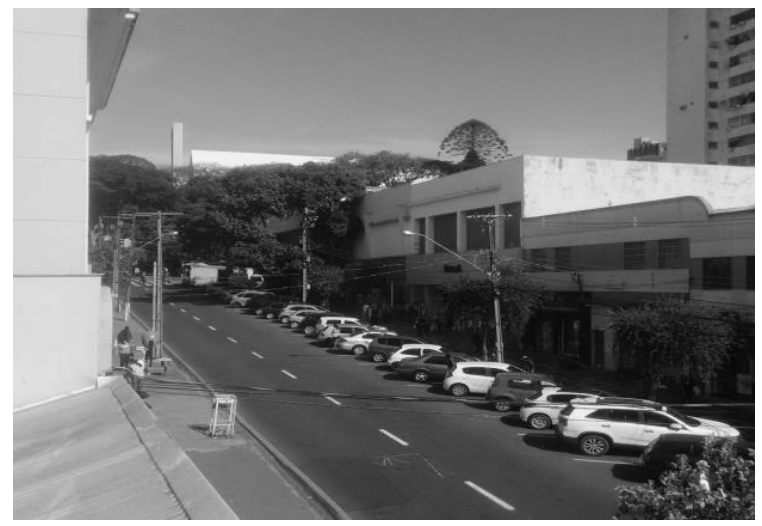

Foto 4: Londrina, 2018.

Fonte: Arquivo pessoal ALMEIDA, 2018.

Fotógrafo: Adriano Almeida.

\subsection{Fixos e Fluxos: o repertório urbano}

Baseados nas afirmações de Santos (1994, 2007, 2008), é possível considerar que o varejo, entendido como elemento espacial que compõe a cidade, se revela como um local fixo privado, e suporte para que os fluxos se construam norteados pelo consumo, pela prática estabelecida como comercial, por meio dos usos dos indivíduos em suas atividades cotidianas.

Identifica-se que constam apenas fixos privados, constituídos por estabelecimentos comerciais varejistas, e que inicialmente, na constituição da cidade, é possível notar casas em nível térreo, ou mesmo construções com estabelecimentos comerciais em nível térreo e moradias nas sobrelojas.

O fluxo de pessoas pode servir como base significante para a compressão da velocidade das transformações do ambiente no objeto pesquisado (SANTOS, 1994). Nota-se um grande volume de veículos estacionados na segunda fotografia, que nos permite inferir que há grande circulação por esta via. No início da construção existiam aqui poucos 


\section{tríade}

habitantes, sendo assim, pouco uso da urbe. Atualmente, nota-se um maior número de pessoas circulando pela via pública, esta movimentação gera maiores conflitos que exigem mais transformações. Santos (1994, 2008) afirma que este elevado fluxo de pessoas se revela por meio da disponibilidade de produtos e serviços, bem como de empregos e de estabelecimentos prestadores de serviços estabelecidos na rua Rio de Janeiro, propiciando constante movimentação de usuários. Este fato gera diferenças qualitativas e quantitativas relacionadas ao consumo, sendo fato gerador do nascimento e manutenção da produção, bem como da distribuição dos bens de consumo, como afirma em seus estudos Santos (1994).

Os locais fixos, nas argumentações de Santos (2007), apenas são suporte para que as mercadorias abasteçam os mais diversos e desconhecidos consumidores. Neles o fluxo fica marcado nas relações impessoais do processo de venda, sem laços de proximidade entre os usuários do fixo público - a via, tampouco pouco laços de familiaridade entre os objetos ofertados (mercadorias) e o vendedor. Assim, Santos (2007) afirma que este formato de fixo e fluxo, viabiliza que o capital circule mais rápido, oportunizando a retroalimentação do sistema, novos investimentos e espaços para novos produtos, mas impossibilitando novas relações entre os usuários.

Nessa análise não se percebe diretamente a presença de fixos públicos, pontos que, segundo Santos (1994), auxiliam em uma análise mais ampla dos espaços. Nas fotografias analisadas, o espaço público encontra-se representado pela rua e pela calçada, sendo por meio da sua constituição suporte da construção em torno de si de fixos privados, e também meio de transição de usuários e suas comunicações. Assim, não menos importante, é o poder público nesta análise do consumo por meio dos varejos, uma vez que contribui de diversas formas para o crescimento e desenvolvimento, aplica seus investimentos em infraestrutura para 
facilitar o processo de consumo, sendo agente responsável pelo fortalecimento da circulação dos usuários e das mercadorias (SANTOS, 1994, 2008).

Constata-se neste recorte, relacionando os fixos e fluxos, a formação de diferentes espaços: rua, estacionamento, calçadas, estabelecimentos comerciais, arborização, entre outros, permitindo compreender suas linguagens e como se comunicam com os usuários do espaço urbano, sendo suporte para expressão da sociedade (SANTOS, 2007). Pode-se afirmar que são os fixos e fluxos que produzem as cenas comerciais e econômicas do varejo, são complexos e dinâmicos, interligados, na construção do processo social, histórico e cultural.

\subsection{História ambiental e sua relação com o usuário}

O espaço pode ser descrito por meio da significação (TORRES, 2014). Seguindo esta afirmativa, é possível compreender que os ambientes públicos possuem força de determinação sobre os usuários, porém, não controlam os efeitos de transformação ocorridos pelos resultados das interações ocorridas nos espaços, sendo estes públicos ou privados, institucionalizados ou espontâneos.

Houve mudanças nas estruturas físicas estruturais dos estabelecimentos; assim, neste conceito, as imagens nos revelam uma continuidade, apresentando a necessidade de observar os elementos e não tão somente ver a paisagem. É preciso entender e compreender seus elementos e dela abstrair as relações significativas, realizando uma leitura pela percepção dos significados dos signos (TORRES, 2014).

É possível notar que os estabelecimentos que se localizavam na parte superior da rua foram substituídos por novos estabelecimentos, com dimensões maiores, atendendo a demanda de espaço físico para diversificação e distribuição de novas mercadorias. 
Já, ao examinar os estabelecimentos localizados na parte inferior da rua, verifica-se que as estruturas físicas estão com poucos sinais de alteração estrutural, preservando características das suas construções. Conforme afirma Ferrara (1988), a transformação dos espaços urbanos está na história da preservação da sua memória. Pela significação dos espaços, é possível avaliar que os estabelecimentos dos varejos se apropriam dos espaços públicos e mantêm em suas características físicas a mesma formatação inicial do comércio na época da colonização: por meio do restauro se preserva o ambiente.

O restauro, enquanto recuperação urbana procura resguardar a memória do passado, do antigo, querendo reviver seu valor, querendo silenciar o presente e deixar falar o valor do passado, sendo um regresso nostálgico ao valor do passado da paisagem urbana, "enquanto paráfrase do passado, o restauro é a reconstrução da memória de um uso enquanto intenção de fazer reviver o passado como fato". (FERRARA, 1988, p. 59).

A relação dos espaços com o usuário está na leitura que ele, como observador, faz dos sentidos e significados, abstraindo o conhecimento para si, sendo necessário que se aproprie dos usos e linguagens desta espacialidade e interaja com eles na construção dos sentidos. Neste processo, constata-se que os estabelecimentos, enquanto unidades comerciais desejam apenas transmitir o cerne da sua existência, o consumo. Analisada as fotografias, compreende-se que os espaços institucionalizados, ou os espaços públicos, se dão sim de forma espontânea. Sobre eles, Londero (2013) afirma que o consumo imagético dos ambientes renovados viabiliza a renovação na percepção do indivíduo em relação ao lugar, que agora emana a imagem que the é de direito, não estando mais condicionado à flexão do apelo comercial. Desta forma, o autor complementa que, uma vez que as restrições que se aplicam à propagação de mensagens comerciais não mais interferem, ativamente, no 
discurso imagético dos ambientes, concede espaço visual para que, os signos dos ambientes urbanos, se sobressaiam.

\subsection{Características físico-contextuais: estágio atual e sua transformação}

Na figura 1, vê-se que o uso de sinais de identificação ou textos de publicidades são inexpressivos ou quase inexistentes na foto 1 , bem tímidos em proporção de tamanho e apelo visual de diferenciação e destaque, observado em comparação aos elementos da foto 2 . É importante salientar aqui, que a cidade de Londrina passou por uma reformulação visual. $\mathrm{Na}$ figura 2, nota-se que os elementos da publicidade na foto 3 , acompanham as informações da foto 1 (figura 1). Por intermédio da implementação da lei "cidade limpa", ocorreu o processo de despoluição visual das fachadas dos estabelecimentos em todos os segmentos do comércio (esta questão não será abordada nesse estudo), exposto na foto 4 da figura 2, o que diferencia a espacialidade central do município de Londrina-PR, se comparada a outras cidades do seu porte, que ainda não passaram por essa ação de ordenação visual.

Constata-se que no decorrer dos anos o sentindo de fluxo para automóveis foi invertido, bem como a largura da rua, que ficou maior, aumentando o espaço para o transito e estacionamento dos veículos, concomitantemente, diminuindo os espaços para circulação dos pedestres nas calçadas, que agora disputam por espaço com o comércio informal, telefone público. Houve alteração no tipo de pavimentação das calçadas, sendo atualizado com um material diferenciado e disposto esteticamente mais bonito, visando o embelezamento do ambiente público e a experiência de caminhar por este espaço, pontos importantes de análises apontados por Ferrara (1988). 
Nota-se que a arborização na década de 1940 ainda não havia sido realizada. Há poucas árvores de grande porte localizadas na parte superior da via, onde inexistem moradias ou estabelecimentos comerciais. Atualmente a via permanece tímida com o volume de árvores plantadas no canto inferior da rua, contraponto ao canto superior da via, onde há um volume considerável de arborização, que auxiliam na climatização do espaço urbano.

Por meio dos inúmeros fios dispostos nos postes de distribuição de energia e comunicação, veem-se signos da evolução tecnológica. Inicialmente, suas atribuições eram de transmitir energia; na atualidade, com o desenvolvimento de novas tecnologias, a quantidade de fios dispostos faz jus a quantidade de informações que necessitam transmitir para atender a demanda social.

Identifica-se que em ambas as fotografias não há placas de sinalização, signos verbais ou não verbais importantes para os usos dos ambientes urbanos. Por meio dos estudos de Ferrara (1998, 2012), podese inferir que na Londrina de 1940 o número de vias públicas era pequeno e não havia identificação das mesmas, uma vez que os pontos de orientações e referências eram os moradores e os próprios estabelecimentos comerciais ou residências. Atualmente, por conta do número elevado de vias públicas, estas informações são imprescindíveis, propiciando informações aos usuários com mais agilidade e facilidade na identificação e interação com o ambiente urbano.

As fachadas são repletas de significado e simbolismo. Verifica-se que os usos urbanos não alteraram a estrutura arquitetônica e as fachadas dos estabelecimentos. A arquitetura do centro da cidade foi influenciada pela cultura dos imigrantes que construíram seus comércios baseados em sua terra natal. A transformação ocorrida está na inserção de novos elementos arquitetônicos contemporâneos à paisagem (FERRARA, 2012). Corrobora com esta informação a inclusão da edificação vertical, representadas nas 


\section{tríade}

imagens fotográficas da última década, utiliza-se dos signos de renovação espacial, recicla, atualiza e desenvolve o espaço, mantendo a ordem já preestabelecida deste ambiente. Assim, o entorno do espaço se manteve inalterado, mas contribuiu possibilitando novos usos do mesmo local.

Devido à disposição das imagens, é possível constatar que os discursos de cada fotografia são inteiramente distintos, dado que a quantidade de elementos visuais da paisagem retratada na foto 2 e 4 contrapõem com a limpeza e claridade dos elementos que compõem a imagem da foto 1 e 3 . Nas últimas, se reconhece na formação visual o sentido de cada elemento disposto coerentemente, sendo a imagem mais confortável aos olhos do seu intérprete.

Identifica-se na imagem da foto 1 , por meio das fachadas, alguns estabelecimentos comerciais pelos signos que nos remetem a armarinhos que comercializam diversos tipos de produtos. Sem segmentação específica, são comércios bem característicos da época. Concentravam-se diversos produtos em um único local, pois existia a demanda de compra, mas não a demanda de estabelecimentos para comercializar todos os produtos disponíveis para comercialização. Atualmente, os estabelecimentos se mantêm direcionados ao comércio, mas a formatação de oferta sofreu alterações para atender a atualização das necessidades básicas humanas geradas pela própria sociedade e pelo desejo de consumo (FERRARA, 1988).

As transformações na espacialidade da urbe londrinenses são diretamente influenciadas pelos estabelecimentos comerciais e seus espaços, em especial, o comércio varejista. Este mesmo sofre alterações pelas mudanças ocorridas nos espaços urbanos. 


\section{Considerações finais}

As fotografias serviram como instrumento de ilustração da imagem da cidade, e, pelos elementos sígnicos dispostos, decodifica-se seus sentidos e significados (FERRARA, 1988). Nisso reside a competência daquele que analisa imagens em paralelo do passado com o presente, dado que a imagem não fala por si só, sendo necessário dialogar com elas.

A imagem da cidade e suas particularidades se manifestam, através de suas relações do antigo e do novo, significações que alteram sua paisagem, fazendo com que os espaços adequem suas linguagens, transmissoras dos seus sentidos, beneficiando os usuários da mesma forma que beneficia o próprio ambiente com a construção diária da sua paisagem. A cidade enquanto objeto vivo constrói sua imagem por intermédio da comunicação, imaginação e percepção do usuário. O usuário é intérprete da paisagem urbana mediante sua leitura: altera a si e os ambientes em decorrência dos seus usos. É necessário que se aproprie dos usos e linguagens desta espacialidade e interaja com eles na construção dos sentidos.

Dos estabelecimentos varejistas e suas relações de consumo emanam signos da cultura local, social e histórica, permitindo afirmar que as transformações na paisagem urbana têm expressiva relação com as modificações que ocorrem nos varejos, desde as estruturas físicas dos estabelecimentos comerciais às heranças culturais.

\section{Referências}

BAUMAN, Zygmunt. Vida para o consumo. Rio de Janeiro: Zahar, 2008. BOURDIEU, Pierre; BOURDIEU, Marie-Claire. O camponês e a fotografia. Revista Sociologia e Política, Curitiba, v. 26, p. 31-39, jun. 2006.

CANEVACCI, Massimo. A cidade polifônica: ensaio sobre a antropologia da comunicação urbana. São Paulo: Studio Nobel, 1997. 
COUTINHO, Iluska. Leitura e análise da imagem. In: BARROS, Antonio; DUARTE, Jorge (orgs.). Métodos e técnicas de pesquisa em comunicação. São Paulo: Atlas, 2012. p. 330-344.

FERRARA, Lucrécia D 'Aléssio. As mediações da paisagem. Líbero, v. 15, n. 29, p. 43-50, jun. 2012.

FERRARA, Lucrécia D 'Aléssio. Cidade e imagem: entre aparências, dissimulações e virtualidades. Revista Fronteiras: estudos midiáticos, Rio Grande do Sul, v. 6, n. 1, p. 21-32, jan./jun. 2004.

FERRARA, Lucrécia D Aléssio. Ver a cidade. São Paulo: Nobel, 1988.

LONDERO, Rodolfo Rorato. Teorias da publicidade e cultura visual: a abordagem informacional de Abraham Moles em O cartaz. In: ENCONTRO NACIONAL DE ESTUDOS DA IMAGEM / ENCONTRO INTERNACIONAL DE ESTUDOS DA IMAGEM, 4. 2013, Londrina, PR. Anais [...]. Londrina: Laboratório de Estudos dos Domínios da Imagem (LEDI), 2013. Disponível em:

http://www.uel.br/eventos/eneimagem/2013/anais2013/trabalhos/pdf/Ro dolfo\%20Rorato\%20Londero.pdf. Acesso em: 10 jan. 2018.

MARCONI, Marina de Andrade; LAKATOS, Eva Maria. Técnicas de pesquisa. São Paulo: Atlas, 2002.

SANTOS, Milton. O espaço dividido: os dois circuitos da economia urbana dos países subdesenvolvidos. São Paulo: Edusp, 2008.

SANTOS, Milton. O espaço do cidadão. São Paulo: Edusp, 2007.

SANTOS, Milton. Técnica, espaço, tempo: globalização e meio técnicocientífico informacional. São Paulo: Hucitec, 1994.

TORRES, Desire Blum Menezes. Supermercado: um não-lugar. Rio de Janeiro: Rizoma, 2014. 